\title{
Re-examining Indigenous Conceptualizations of Family and Community Involvement
}

\author{
Jeremy Garcia \\ University of Wisconsin-Milwaukee
}

\begin{abstract}
In this article, I highlight the importance of schools and educators serving Indigenous children and youth to draw upon the power of family and community engagement that is culturally defined and guided by Indigenous values and knowledge systems. In addressing these concepts, I draw upon my own personal narratives and current research with American Indian families in an urban setting. The expectation of this research was to develop an understanding of how parents respond to a process of constructing healthy and purposeful relations between the home and school for student success among American Indian families living in an urban setting. Throughout, I use the terms Native American, American Indian, and Indigenous peoples interchangeably. Native American and American Indian refers specifically to Indigenous peoples of the United States. When I use the term Indigenous peoples, it is intended to reflect people joining in the global effort to decolonize their worldviews and reposition our epistemology and ontology.
\end{abstract}

When we are able to see beyond Western paradigms also shaping our views of ourselves, we may be able to regenerate rituals and the origins of our indigenous knowledge systems in new cultural, political, and epistemological spaces.

Indigenous peoples have theories that articulate origins of knowledge, and we have ways of purposefully regenerating these origins in our contemporary technological societies.

(Tarajean Yazzie-Mintz, 2008, p. 18) 
Early within my career, I had a desire to work with and support notions of parent involvement within schools serving Indigenous peoples. While at Northern Arizona University as an undergraduate teacher education student, I had an opportunity to design and implement a research study with parents located between two diverse schooling and community contextsone located on the Hopi Tribal community in Arizona and the other within an urban setting. In this study, I wanted to understand the potential differences in how each school worked with parents so as to improve my own understanding, as a future elementary teacher.

Results from the study reflect some good insights into how each school supported the diversity of families; however, what remained at the forefront of the data is how these schools continued to define parent involvement from positions of being actively present as volunteers in the classroom, chaperones, and participants in parent teacher organizations. I acknowledge the general notions of involving and interacting with families as volunteers and attending parent teacher conferences is important; however, in many instances family differences lead to notions of marginalization that are reflected in concepts of language, power and culture. As a result, I find that continued analysis is needed within the ways in which parents from diverse backgrounds, such as ethnicity, race, gender, and class, are involved in schools that are generally framed within white-middle class structures (Grant \& Sleeter, 2007). Specific to Indigenous schools, missing is the importance of having a working conceptualization of how they engage with families and communities from an Indigenous epistemological context that is grounded within Indigenous values and knowledge. The history of colonialism and assimilation has impacted our Indigenous communities; therefore, there also needs to be opportunities for educators, parents and community advocates to re-conceptualize what it means to be guided by an Indigenous framework for family involvement in schools. Tarajean Yazzie-Mintz (2008), an Indigenous scholar who currently is the Program Officer for Wakanyeja "Sacred Little Ones" Early Childhood Education Initiative of the American Indian College Fund, states that "when we are able to see beyond a Western paradigm shaping our views of ourselves, we may be able to regenerate rituals and the origins of our indigenous knowledge systems in new cultural, political, and epistemological spaces" (2008, p.13); which includes how we engage with Indigenous families and schooling contexts.

\section{Indigenous Education and Family Involvement}

In my personal experience as an Indigenous teacher and having engaged in dialogue with many educators of Indigenous students, it is apparent that there exists an on-going desire inherent in the voices of educators and community members to re-conceptualize and contextualize notions of family/community partnerships in Indigenous schools. Generally, the schools serving Indigenous communities tend to reflect efforts to only involve parents within notions of volunteering, attending parent conferences, donations, support of homework and attendance at school functions. Another related phenomenon among Indigenous schools is the adoption of programs that are framed in providing training to parents within areas of parenting skills, child development, job training skills and, developing understandings of home to school expectations. For example, The Family and Child Education (FACE) program is a program that is supported by the Bureau of Indian Education (BIE) and was started in 1991 in affiliation with the Parents As Teachers National Center and the National Center for Family Literacy. Accordingly their goals are: 
to support parents/primary caregivers in their role as their child's first and most influential teacher; to increase family literacy; to strengthen family-school-community connections; to promote the early identification and services to children with special needs; to increase parent participation in their child's learning; to support and celebrate the unique cultural and linguistic diversity of each American Indian community served by the program; and to promote lifelong learning (see website at http://faceresources.org/).

Currently, the FACE program is implemented within 46 schools predominantly within the states of Arizona and New Mexico. The goals reflect a concerted effort to address the opportunities for families to engage with schooling contexts; however, I question the potential limitations of such programs in terms of how they interpret the history of colonialism, assimilation and the promotion of Indigenous values and knowledge systems. For instance, I question from what perspective family literacy is being conceptualized. How might notions of funds of knowledge across homes, families and communities (Gonzalez, Moll \& Amanti, 2005) inform this process? While the FACE program is one among others that deserve further examination, I return here to the importance of a critical analysis of how we arrive at understanding family involvement from diverse contexts - namely Indigenous peoples and communities.

Specifically, such query falls within problematizing the impact of colonialism and assimilation upon partnerships with family and community in schools; notions of empowerment that lead to self-determination and sovereignty for American Indian peoples; and the re-centering of partnerships that is informed by Indigenous knowledge systems and ontologies (Jaime \& Russell, 2010; Kaomea, 2012). The desire to build partnerships between parents, guardians, and community members is an ancient, yet contemporary, concept that is informed by relationships defined by clan associations, tribal affiliations and relationships to land and ecological systems that reflect how American Indian peoples determine their existence (Battiste, 2000; Barnhardt, \& Kawagley, 2005; Benham, 2008; Garcia 2008a, 2008b; Yazzie-Mintz, 2008). I now turn to my own Indigenous community to offer a space of possibility that informs how the Hopi epistemology informs my conceptualization of family and community involvement.

\section{Indigenous notions of Family and Community: A Personal Narrative}

As I continue to return to my home village of Sitsomovi, located among the landscapes of the Hopi tribal community in northern Arizona, I am reminded of the power of family, community and the interconnectivity that defines notions of relationships. In many situations, I find myself in discussions around the upcoming ceremonies and social gatherings that reaffirm our roles and responsibilities - shaped by the complexities of our clan affiliations and cultural obligations. In these contexts, I observe the strength and value of how notions of support, appreciation and commitment to sustaining our partnerships and relationships is defined by our Indigenous values and cultural practices. Such relationships, support, and responsibilities are shaped at the outset of our lives as we enter this world during a Hopi baby naming ceremonyTiiqatsi - which reflects a moment of celebration and honors the rejuvenation of life. Shared elsewhere (Garcia, 2008b), I have provided insight into the naming ceremony of my first daughter, Toovuhongsi, where the emotions and lessons of a being a father came to fruition. In this previous narrative, I pondered the questions of "how will I know what to do? How do I care for my daughter? What are the roles and responsibilities of a father? [and] how do I teach her to 
walk proudly as a Hopi in a contemporary world?" (2008, p. 25). These simple, yet complex, questions recently reemerged with my second daughter, Sonwai, as she was provided the same experience with the Hopi naming ceremony.

In each case, my daughters were shielded from Dawa (sun) for 20 days upon which they were properly introduced after my family_primarily members of the Hoaspoa (roadrunner) clan-came to wash their hair with their Tutsmingwu (white ear of corn representing her mother) and offered a Hopi name. This is one of many initial phases that reaffirms a sense of commitment and a formal acknowledgement of our collective roles and responsibilities as a clan and as extended family to our children. Though we may perceive this ceremony as one in which we formally introduce our children to the world with many blessings, in many respects it speaks to a larger expectation - that requires each of us to live into the roles of supporting and nurturing our children throughout their lifetime. Returning to my initial questions above, the complexities of understanding my role requires that I also reflect on and make conscious the lessons learned from family and cultural contexts that guide and shape how I will engage with my daughters, nieces, nephews, god-children, and clan relatives. The answers are embedded in understanding my relationship to extended family through a cultural lens; which means being conscious and intentional about how I enact my support for my family.

While this is one ceremony that provides a unique outlook to how Hopi people conceptualize notions of family, it provides a critical perspective on how schools can come to understand what is meant by parent and family involvement that can be shaped from an Indigenous context. During these moments of observations and dialogues that contextualize our relationships, I often ponder the questions of what can this mean for how we conceptualize parent or family engagement within western schooling constructs of education? How might schools serving Indigenous children and youth reshape how they frame notions of parent or family engagement from an Indigenous perspective? In considering this process, how might this approach begin to disrupt notions of treating parents as uninvolved or deficient, and begin to privilege Indigenous families as a source of strength and commitment to education from an Indigenous and western context?

In reflecting on my time spent among my own Indigenous community, I see opportunities for schools to begin rethinking how they begin to think about family involvement from an Indigenous perspective. Essential to this process is understanding the contexts within which Indigenous students are situated — urban or rural, reservation settings. In each context, a critical component is examining how the history of colonialism and assimilation may be impacting how parents interact with schools; and importantly, how might Indigenous notions of relationships inform how schools conceptualize family and community involvement. The following study is contextualized within an urban setting and focuses on the process parents encountered as they engaged in the co-construction of whole schools events.

\section{Indigenous Qualitative Research}

This Indigenous qualitative research study (Kovach, 2009; Smith, 2012; Wilson, 2001, 2003), which stemmed from an Indigenous theoretical orientation and privileged Indigenous values and knowledge (i.e., history, stories, ceremonies, language), examined the varying perspectives and experiences of American Indian parents and educators located in a Midwest school serving American Indian K-8 ${ }^{\text {th }}$ grade students and families in an urban setting. The school 
has an average enrollment of 300 students from various tribal affiliations within the region. All students who attend this school must be enrolled in a tribe.

In offering support for prior work with the school, discussions with the administration emerged around building a school community that had a shared sense of understanding and ownership of the school values and mission, which led to creating opportunities for parents to become involved with the school. As a result, this study involved a series of interactive opportunities for parents and teachers to co-construct whole school activities; specifically, examining how Indigenous parents and educators contextualize the process and experience of engaging in opportunities to collaborate with educators. The research also explored how family partnerships can be rooted within an American Indian cultural framework that honors both tribal knowledge and education within a schooling context. Specific research questions examined are 1) When given the opportunity to build relations, how do parents and educators contextualize the process and experience? How does this inform next steps in constructing healthy and purposeful relations and partnerships for student success?; and 2) How can parent involvement be rooted within an American Indian cultural framework that honors both tribal knowledge and education within a schooling context? While the study offers many areas to examine, within this article I focus on the lessons learned from the process of co-constructing whole school activities.

\section{Methodology}

The research was conducted over the course of the 2012-2013 academic school year. The study involved 6 parents and 3 educators (a 7th grade teacher, a cultural teacher and an educator who worked with families) who were part of an American Indian school in the Midwest, which I refer to as the Indigenous Midwest School. Data collection included pre-post interviews and observations of the planning meetings for three whole school events. Planning meetings included an average of 3 sessions prior to the implementation of the whole school event. Data also included observations of parents and educators at the planned whole school events. Pseudonyms are used for all participants and the school. Within this article, I specifically focus on one educator and three parents who participated in the study:

- Sandy is an educator who works with families within the early childhood setting. She is a non-native educator with a background in social work and had limited interactions with Indigenous families and students prior to her employment with the school. She has been with the school for over 5 years.

- Alex is an enrolled member of the Oneida Tribe and a father of a student who has been attending the school for 2 years at the time of the study. Alex is married to a non-native who is also active with school functions.

- Carol is an enrolled member of the Creek tribe and the mother of 3 students who attend the school. Her husband is a non-native and is active with the school. Their children have been attending the school for 3 years.

- Amber is a Native-Hawaiian who has lived within several states on the west coast prior to moving to the Midwest. Amber and her husband (also a non-native) have 1 child attending the Indigenous Midwest School. 


\section{Theoretical Framework: TribalCrit}

The theoretical framework that guided this study is Tribal Critical Race Theory (TribalCrit) (Brayboy, 2006). TribalCrit honors contemporary and ancient Indigenous knowledge systems as a way of understanding our political, social and educational goals to develop a schooling experience that assists in meeting notions of self-education, self-determination, and tribal sovereignty. The theoretical framework derives from orientations of Critical Race Theory, with particular emphasis on counter-narratives as a point of value and reality that resist or speak back to positions of power (Solorzano \& Delgado Bernal, 2001). "Critical Race Theory values experiential knowledge as a way to inform thinking and research. As a result, narrative accounts and testimonies are valued as key sources of data by CRT scholars" (Brayboy, 2006, p. 428). Framed within education, Critical Race Theory was created to analyze and confront racism facing people of color, with an underlying position analyzing how racism is prevalent in learning institutions and society (Ladson-Billings, 2000). When contextualized within American Indian policies, the history, education and sovereignty of American Indian communities, notions of Critical Race Theory take on new meaning - as American Indian tribes have legal and sovereign relations with the United States. Considering the effects of history, notions of colonization and assimilation become prominent aspects that continue to impact Indigenous peoples. As a result, honoring Indigenous knowledge and stories as valid and resourceful ways of knowing assist in guiding how Indigenous peoples will co-construct our own theories that shape how we will live into notions of tribal self-determination and sovereignty.

It is within this framework that the study was guided in rethinking how the participant narratives can re-conceptualize the ways in which parent and family involvement can be deconstructed among Indigenous peoples.

\section{Findings}

The following findings reflect historical (colonialism/assimilation) impacts on access to cultural knowledge and Indigenous conceptualizations of family and community; inter-cultural family dynamics limit participation of non-Indigenous family members; and notions of empowerment and ownership in co-constructing activities that lead to larger shifts shaped by a collective solidarity for American Indian self-determination and sovereignty. In this article, I focus on a few prominent themes that emerged with American Indian families living within an urban setting.

\section{Problematizing Identity: Pathway to Unpacking History}

Each participant provided powerful and meaningful connections to their lived realities and experiences of living within various contexts that shaped how they would engage with their Indigenous ways of being through culture and language. In each case, there is a sincere effort to make sense of how the history of colonialism and assimilation have impacted their Indigenous identity. Such a space is critical, as, the opening words of Yazzie-Mintz (2008) suggests, "When we are able to see beyond Western paradigms also shaping our views of ourselves, we may be able to regenerate rituals and the origins of our indigenous knowledge systems in new cultural, political, and epistemological spaces" (2008, p. 18). This is where we begin. A theme that 
emerged is contextualizing how history has impacted our current realities. I share here Alex's reflection; he is a father of a student at the school who offered a personal reflection:

She [my wife] was very excited that [our child] got to go to this school. There is a couple times when we [my wife and I] first met, and we would go to [local American Indian festival] and walk around. And there was a couple times I didn't know how I was supposed to feel about being Oneida, because my dad never talked about it for various reasons. When he was growing up there [Midwest region] in the 30's and 40's when there was a different socio-economic view point. At that time, there was still the boarding schools. You still had people telling you, "you're not native, you're... whatever we tell you, you are." So my dad really rebelled against that and it took a lot for me to get involved - into the culture. I know...I know a couple grains of sand on the beach of what the culture is. I am still learning.

Throughout the interviews and planning sessions for the events, we can find each Indigenous participant self-reflecting on their own sense of Indigeneity. At the outset, many have shared a journey that encompasses many locations, from living within a tribal reservation to moving between major cities throughout the Midwest and intermarriages. It is through this reflective process on their own life that a conscious understanding of their identity began to take on new meaning. While the debates and politics surrounding American Indian identities are beyond the scope of this article (see Gonzales 2001; Grande, 2004; Lomawaima \& McCarty, 2006; Smith 2012); what emerges here is the importance of providing families and educators an opportunity and a space to reflect on the complexities of their own Indigenous identities; particularly in relation to the history of assimilation and colonization.

In her opening interview, Carol reflects on her time growing up within her tribal community in her early years, but had a shift in living and attending school within urban settings. For instance, she attended a public school, while her sister attended a boarding school, in a small town in the Midwest. Once her mother re-married, they moved to a large city due to employment, where Carol finished high school and no longer had regular connections to her culture and community. After Carol got married she then moved to her current location in an urban setting in the Midwest where her husband works. Consider Carol's reflection on how her distance from family impacts her identity:

And I mean it's always nice when we share some really good and fun stories and stuff like that, there's no ill will or anything... it's just we don't have a close relationship. And it's, I find that with like my brothers and sisters, other than my brother and my youngest sister... those are the two that I have the closest ties to, and the rest of the family,...aunts, uncles, I don't really see them very often. I don't communicate very often.

As a result, over the years she has worked to sustain connections to family, yet we see living apart from extended family decreases her ability to remain connected. It is these forms of selfreflection on their home and schooling experience that generated the initial thought process of how moving from various locations due to jobs or intermarriages have impacted their connection to their Indigenous family and cultural practices. The following captures the ways in which the participants continued to unpack notions of history affecting Indigenous families. 


\section{History: Understanding the Nuances}

I continue with Carol's initial impression and reaction to the Indigenous Midwest School. Carol had moved from another urban setting to the Midwest and was new to any educational context and services that directly worked with Indigenous students. She reflects:

While I was driving around one weekend and I happen to pass this facility. The gates were closed but I saw the sign outside and it read, [Indigenous Education School]. I thought, well they probably have like a correctional facility for our little Indian children, you know. Because that's all they ever had been involved with. The schools that my sister went to, they were boarding schools and they were always...she got kicked out...there were so many fights and so all of that just kind of like,...that's the negative part that I remember.

Carol's initial reaction to the school, that it should be a "correctional facility for our little Indian children" is worth continued analysis in terms of how it reflects notions of a deficit mindset. We can see how our past encounters with families and their experiences with boarding school issues altered the perceptions of this new educational facility that takes its role of service and education seriously. Such reactions and realities are important points of consideration and deserve on-going analysis.

In her role as an educator working with families, Sandy reflects on how knowing the history of colonialism and assimilation is important in understanding her work with families from an Indigenous background.

I think it helps to kind of put it in perspective where the breakdowns are and why people might be non-trusting or where they're coming from. It helps figure out how you're going to approach it and not take it personally....It may not even be like a conscious thing that they're thinking, like this is why I'm acting this way. Just like the boarding schools and the whole parenting issue and not being parented, or institutionalized, and how that has affected parenting today for a lot of our families....kind of puts it into perspective. And it helps you come at it in a different way, I guess, rather than, wow, they just don't want to be involved. I think it helps to have that history....It makes you think about it differently, like yeah, they just can't get over it. It's a generational thing, so it does help you in how you view people and where they're coming from.

Sandy's reflection on her engagement with families is critical. Amongst the framing of this dialogue, Sandy provided her own personal growth in dismantling the commonly made statement, "why don't they (American Indians) just get over it (history)"; a statement she admits she held prior to working with the Indigenous Midwest School. Her recognition of the importance of having an understanding of the history provides context and a lens through which she began to understand the nuances of why families may react the way they do. Adding to this notion of understanding the interactions between history and current family dynamics, Amber's observation of participants encourages her to return to the history of colonialism.

In her reflection on the process of being involved with the planning of events, Amber began engaging with a deeper analysis of the ways in which Indigenous families interact or avoid interacting with schooling contexts. She states:

Some generations today have experienced the boarding school...so I think that depending on, and even if somebody themselves hadn't experienced that form of schooling and that 
form of oppression,...that gets passed onto us, right? The way that a family organizes themselves, which is how they talk, how they censor the way they talk, how they edit themselves, just their communicational patterns and their interactions and then, how they organize themselves... and then, take that one step further in how their behavior is done, are developed through that organization. It might seem like where does that self-editing and self-censoring come from? Where did this kind of like, this distrust come from? Well, it comes from like this, the machine of the years of oppression. So, it's how people are organizing their behaviors.

Amber's analysis provides an interesting perspective regarding self-censoring or selfediting and its possible connections to the on-going, as she calls, "machine of the years of oppression" that may have affiliations to the history of assimilation and boarding school encounters that marginalized Indigenous students and families have experienced. She continues this analysis with regard to the urban setting within which she resides and where this school is situated.

Just because somebody says [self-identifies] they're Native American or they're First Nation, or they may say their tribe affiliation, which is their more traditional,... some don't even know their tribe, right? Many of them still don't know that. They still don't know how they got organized that way. "Why are you living in the city and not on a reservation? Did you think about that?" Well, no. I've just always lived here in [urban city]." "Really? Well, three generations ago, you didn't." I mean, but that connection isn't there. It's become internalized oppression.

Amber raises an important process to consider when working with American Indian families in urban communities. The complexities in understanding the depth of one's cultural knowledge and access to knowing and critically analyzing the effects of colonialism and assimilation deserves further examination, framed in the simple yet complex question of "Why are you living in the city and not on a reservation?"

Understanding this history and how "colonialism is endemic to society" and how "governmental policies and educational polices toward indigenous peoples are intimately linked around the problematic goal of assimilation (Brayboy, 2006, p. 429); to use Sandy's words - "it puts it into perspective" and we "can't just get over it".

\section{Understanding Our Role: What happens when we are given freedom?}

A key aspect of this initiative was to offer an opportunity for parents to co-construct 3 whole school family events throughout the academic year. Within this context, the educators and I entered this with a shared understanding that we wanted the parents to have a sense of ownership and freedom to offer their ideas. Though we had this understanding, we did not unpack this in great detail, as I also wanted to see the ways in which the educators engaged with the process. Within this section, I present responses of two parents in regards to the opening process.

Carol reflects:

At first I kind of struggled with my position where what was really expected or what was not, if I was crossing the line or, and I knew after that first program I think that it opened the doors a little bit more that it was a collective group effort and not just somebody 
saying well, Carol, you need to be by this door at this time, you need to fold 100 papers... it wasn't something that was delegated to me....

[The administrators] were willing to put forth the administrative persona, but take a back seat to us parents. I mean, they were willing to go ahead and say okay we'll be here and be there to help, however, find whatever it is that you need to have us do, but we're relying on you to fuel it.

Carols' reflection indicates tension with the process in several ways. Of particular interest are the ways in which power is being dismantled. Certainly, power is reflected in her own discomfort with whether or not she was crossing the line. Critical to her reflection is her observation of how the administrators in attendance were navigating notions of power. She recognized they were willing to take a back seat and to nurture a space where aspects of delegation were minimized. She further suggests:

After the first one [meeting] I really felt a group sense that we were all wearing the same hat and that even though, because I hadn't worked with the administrator or some of the other teachers that had more education, so I guess that was another thing. That I didn't have the education level as these other individuals, so maybe I didn't feel like what I had to say was going to have as much value. But after, like I said, after that first one and the fact that we all put forth a notion or an idea or something like that,...that it was a collective group effort, that's when I knew that what I had to say did matter to somebody.

Another aspect of power emerges in her own self-conscious feeling of having less education than the educators and the impact of that on the value of her insights. This feeling was disrupted as the process of developing a shared ownership through valuing the contributions of all parties involved developed.

We can see similar forms of anxiety within Amber. Amber raises another interesting perspective in regards to problematizing Western and Indigenous concepts of dialogues and interactions. She reflects:

"Do what you guys want to do. Whatever you want to do." Then we were like looking at each other like, "Okay." Of course, there's always just that anxiety about, "Okay. We don't know what we're getting into, but we know we want to help. We know we want to do something for our community, so how do we make this happen? How do we have this dialogue?" .... I think that that came naturally, I do. I didn't feel like anyone had to tell anybody, "This is how we should communicate to each other." I think our ideas going in, we definitely had that more West - I always keep saying Western ideology - that idea of how academically we should go into a conversation, note pad, paper, linear thoughts. I think once we broke ourselves free of thinking that we had to organize things that way and we could just talk in a safe place, I think that is when it became something different and we were able to have that dialogue.

Amber's reaction to the space to freely engage comes with some uncertainty as she, too, questions how much freedom they had, and in subtle ways is questioning the reality of the ability to freely engage in the process. Once she recognized the opportunity to share her ideas, she immediately shifted to examining what this means for the form of dialogue between the participants. Her analysis is framed within unpacking notions of western and Indigenous ways of 
engaging in dialogue. Amber's statement that notions of "breaking free from that [western] thinking and organization" created a safe place is a powerful point of analysis. Her experiences emerge from having engaged with other schooling contexts, which she continues to capture here: Unlike other communities, when I worked at a Montessori school, we had predominantly white families. When we would get together to talk about stuff like this, the voice was different. I can only make a connection from my own personal experience, but it was, I mean, the moms, the dads, whoever was participating, it was like, "Why don't we do this? I think this is what we should do?" Then, it was somebody else, "No, I don't know if I like that idea." The debate was actually even more energized. There was a lot more room for disagreeing and I think that's also a Western, a West kind of thinking, right? The West kind of thinking, the idea of ideas coming from who has the greatest idea, then, who bounces off. Whereas I think within the Native American community... where that comes from, many times you see that these ideas just kind of circulate. There's room to have disagreeing, but yet, it's not so confrontational.

Amber has a unique perspective, a critical perspective that shapes how she is interacting with the schooling context. Threaded within her latter responses, she is problematizing the differences between Indigenous and Western epistemological ways of being. She reminds us of the need to continue to examine the ways in which the "Native is contemporary" (Benham, 2008) while still drawing upon ancient knowledge systems. Amber's analysis raises the possibilities of reexamining how Indigenous knowledge and values (i.e., defined by ceremonies, relationships/ clanships) inform the ways in which the participants engage with one another and how Indigenous concepts may guide the dialogues and ideas in the contemporary schooling context.

\section{Embracing Ownership: Collective Synergies}

Throughout the process, there are many instances where the participants were challenged to work at embracing the socio-cultural aspects of each participant; such as the personalities, values, belief systems and experiences they each brought. Some of these experiences were shaped in notions of funds of knowledge, where individuals and families "have knowledge, and their life experiences have given them that knowledge" (Gonzalez, Moll, Amanti, 2005, p. x). These life experiences are informed by the larger social contexts (i.e., history, policies, and political views) and daily encounters with the world in which they live. Some were grounded in traditions of their specific American Indian cultures. However, within this context of examining one another, they began to understand the importance of developing a shared sense of ownership that contributed to supporting and honoring one another's voice. Consider Carol's recollection of how she embraced another parent's perspective. She states:

I just think that we had some really good leaders and even though one of our moms, she was really, really quiet, but she had some really powerful [emphasis add] suggestions.

And so whenever she would put forth, you could tell that she's not one that was out there speaking all the time. Like me, I'm like da-da-da-da-da, speak every chance I got! But whenever she had something to say, you knew it was going to be something that was important. 
Alex also suggests:

This was the first time we have done this, and it wasn't like one person dominating the conversation. I know the administration was there leading, but everyone had a chance to speak, everyone's opinion was listened to, everyone was respected, well can't say we all valued what was shared, but they were respected. Everyone had a voice, and that is rare in meetings in any school function.

Finally, Amber, analyzed her own position and perspective on honoring and respecting the fellow parents in the process. She reflects:

To see the parents feel more confident in their voice, I think that people do a lot of selffiltering. Obviously when there's people like myself and other people that were part of the group who don't mind offering ideas and talking. Sometimes that can become, I think, also intimidating for people that maybe have ideas, but then are not sure how to...they keep constantly censoring and filtering what they're saying and editing; that self-editing where you're, "Oh, I don't know if I should say that. It might sound stupid." So, it'd be nice to see parents have a safe dialogue.

So as the parents continued to navigate the process across multiple meetings throughout the year, they began to develop unity and support that was framed within forming a small community that understands the power of their voice. In essence it began to transcend into aspects of healing.

\section{Healing: Reconnecting to Cultural Traditions}

An on-going expectation that is threaded within the Indigenous Midwest School is the drive to privilege Indigenous knowledge and value systems. This certainly emerged as a theme threaded within the planning sessions; which triggered aspects of "talking story" (Benham, 2008) where personal narratives were shared that shaped the direction of the whole school events. In many respects elements of healing the negative encounters with history, policies, and schooling experiences emerged. Equally important was the participants seeing the flexibility and freedom of this space to explore their own areas of interests-developing a stronger cultural identity. For instance, Carol reflects,

So it's, I'm just finally feeling like my circle is starting, because with the kids learning, the things that I said that I wanted to do, I'm starting to do. At home the kids, they have looms and they started beading on their own. I'm like, hey, here's a loom, you, show me what to do. I go, I've done it before but it's been a long time.

Amber also frames this within a personal but also a larger context of the whole school community. She reflects,

I just think that when we were trying to put these programs, the program together, that that was very evident, putting together with our native type grass root effort to make sure that the people involved were promoting growth of or native, our heritage....I think you could see the community was like really interested. I had people share their story that 
maybe I have never even seen or met in the school and they're just telling me things like, "I remember my grandfather that was Oneida and he used to tell me these stories and this room makes me think of him." There were these things that are there that I think it was bringing more of a connection back.

Within the process of healing, Amber promotes the importance of returning to Indigenous concepts of being. This is evident in the continued purpose of working to privilege Indigenous values and knowledge to guide each whole school event. For instance, the last whole school event focused on well-ness which included a return to traditional foods, traditional games and concluded with an Oneida social dance that contextualized the power of Indigenous knowledge and spirituality. Amber recognizes that the community as a whole is ready for the opportunities and spaces that will generate cross-dialogues that are opportunities to heal.

\section{Cross-Generational Dialogues: We All Need Encouragement}

In the end, we also need to conceptualize what this means for our students. The goal was to offer parents opportunities to develop a sense ownership within the school; however, larger implications of how such a process re-ignited the importance of achievement and support of students within a framework of Indigenous values. While reflecting on a specific moment during the events, Amber recalls her observation of dialogues among parents and their children.

The children that were involved had the sense of pride that these are things that they could still do what may have been played or processed way back when, that they have that sense of ownership of who they are. I think that it incorporated growth into mainstream life because I believe that what we were trying to instill into our parents and to our children was positive growth and who they are, to recognize that, hey, I am native, I am strong, I am smart, I am, I am, all of these things. And I still have to live in this day and age but I can promote a better picture.

In summary, in Carol's own words, "As much as our children need encouragement, our parents need that encouragement also. So I think our ultimate goal is to make sure that all of our students and families feel good about themselves."

\section{Implications}

I am honored to have learned from the counter-narratives that have emerged. The intent of this work was to understand how parents respond to a process of constructing healthy and purposeful relations and partnerships for student success among American Indian families living within an urban setting. What has emerged is the importance of understanding how the past continues to shape our current realities. Threaded throughout are the complexities of understanding what it means to be American Indian in a contemporary world that has roots in notions of colonization and assimilation. In what follows, I briefly provide implications that have emerged from the themes generated in this study. The implications suggest possibilities for having a working conceptualization of Indigenous notions of family engagement. 
A. Contextualizing History within Ourselves, Schools, and the Moment.

When working with Indigenous peoples in our schools, we need to be mindful of the hegemonic ways in which colonialism and assimilation have impacted who we are. We must honor the experiences and cultural understandings that Indigenous peoples may (or may not) bring with them into our schools and classrooms.

B. Creating Spaces for Dialogue: A Sense of Ownership and Validation Though the collaboration affiliated with this research was framed within co-constructing events for the school; what we learn is there needs to be spaces of opportunity for families to engage in dialogues that are safe and purposeful. This means acknowledging that Indigenous peoples need to share their stories, their version of history, and their current values that shape the future for their own Indigenous children. As noted in the counter-narratives, it has provided feelings of ownership and validation.

\section{Respecting the Indigenous Family Dynamics}

The complexities of understanding the Indigenous family dynamics that make up our Indigenous communities need further examination and consideration. In particular, how are we conceptualizing the intersection of race, religion, age, language, cultural knowledge, and levels of assimilation that cross the boundaries of our homes and schools? There is a need to problematize the ways in which American Indian cultures and families are marginalized by how various tribal communities are essentialized.

\section{Generating a Collective Community}

While we need to unpack the diverse family constructs among Indigenous families, we also must be mindful of the larger framework of developing a collective solidarity that works to counter inequitable circumstances our Indigenous families are facing.

E. Cross-Generational Healing Process: A Return to Indigenous Knowledge

Understanding that assimilation and colonialism has entered the minds and spirit of how we navigate our lives in a contemporary landscape; there is strength in acknowledging that we have survived and that our stories (ancient and contemporary) have a place in guiding how we engage with families, schools and community. The return to Indigenous values, knowledge, and ceremonies can be our theoretical lens that guides how we relate to families in education.

Emerging from the time, energy and commitment that the parents in the study offered, we are encouraged to rethink how history has "influenced your thinking, because it has." (Meyer, 2008, p. 219). Without recognizing this and having dialogues, the choices and pathways to involving parents and communities to support our Indigenous children may fall victim to continued forms of marginalization. 


\section{Conclusion}

I think in order for us to get there, to get to a place where we can have the education and the sovereignty of what we want our schools to even function as for Indigenous Midwest School, I think we need to first say, "Let's learn together. Let's eat together. Let's dance together."

(Amber, participant)

In conclusion, it has been a privilege to have learned from the parents, family members and educators in this study. Like my own daughters' entrance into this world, we can continue to draw upon our traditions and Indigenous theories to shape how we interact with schools and families - whether we reside on reservations or in urban settings. If we can have sincere dialogues within safe contexts, we can see the origins of our oppression, coupled with a renewed spirit to "learn together, to eat together, and to dance together". 


\section{References}

Battiste, M. (2000). Reclaiming indigenous voice and vision. Vancouver, Canada: University of British Columbia.

Barnhardt, R., \& Kawagley, A. O. (2005). Indigenous knowledge systems and Alaska Native ways of knowing. Anthropology and Education Quarterly, 36(1), 8-23.

Benham, M. (2008). Indigenous educational models for contemporary practice: In our mother's voice, volume II. New York, NY: Routledge.

Brayboy, B. (2006). Toward a tribal critical race theory in education. Urban Review, 37(5), 425446.

Family and Child Education, Retrieved March 1, 2014, from http://faceresources.org.

Garcia, J. (2008a). Honoring our roles as fathers. In M. Benham (Ed.), Indigenous educational models for contemporary practice: In our mother's voice, volume II (pp. 24-27). New York, NY: Taylor \& Francis.

Garcia, J. (2008b). Cultural partnerships confront school culture. In M. Benham (Ed.), Indigenous educational models for contemporary practice: In our mother's voice, volume II (pp. 169-184). New York, NY: Taylor \& Francis

Grande, S. (2004). Red pedagogy. New York, NY: Rowman \& Littlefield.

Grant, A. C., \& Sleeter, E. C. (2007). Doing multicultural education for achievement and equity. New York, NY: Routledge Taylor \& Francis.

Gonzales, A., (2001). Urban (trans)formations: Changes in the meaning and use of American Indian identity. In Lobo, S., \& Peters, K. (Eds.). American Indians and the urban experience. (pp. 169-185). New York, NY: Altamira Press

Gonzalez, N., Moll, C. L., \& Amantis, C. (2005). Funds of knowledge. Theorizing practices in households, communities and classrooms. Mahwah, NJ: Lawrence Erlbaum Associates.

Jaime, A., \& Russell, C., (2010). Reaching Native American families to increase school involvement. In Marsh, M. M., \& Turner-Vorbeck, T. (Eds.). (Mis)Understanding families: Learning from real families in our schools (pp. 145-161). New York, NY: Teachers College Press.

Kaomea, J. (2012). Reconceptualizing Indigenous parent involvement in early educational settings: Lessons from Native-Hawaiian preschool families. The International Indigenous Policy Journal, 3(4). Retrieved from: http://ir.lib.uwo.ca/iipj/vol3/iss4/4. 
Kovach, M. (2009). Indigenous methodologies: Characteristics, conversations, and contexts. Toronto: University of Toronto Press.

Ladson-Billings, G. (2000). Racialized discourses and ethnic epistemologies. In K. Denzin \& Y.S. Lincoln. (Eds.). Handbook of qualitative research ( $2^{\text {nd }}$ ed.) (pp. 430-460). Thousand Oaks, CA: Sage Publications.

Lomawaima, K. T. \& McCarty, L. T. (2006). "To remain an Indian”: Lessons in democracy from a century of Native American education. New York, NY: Teachers College Press.

Meyer, M. (2008). Indigenous and authentic: Hawaiian epistemology and the triangulation of meaning. In N. K. Denzin, Y. S. Lincoln, \& L. T. Smith (Eds.), Handbook of critical indigenous methodologies (pp. 217-232). Thousand Oaks, CA: Sage Publications.

Smith, L. T. (2012). Decolonizing methodologies: Research and Indigenous peoples $\left(2^{\text {nd }} \mathrm{ed}.\right)$ London: Zed Books.

Solorzano, D. G., \& Delgado Bernal, D., (2001). Examining transformational resistance through a critical race and LatCrit theory framework: Chicana and Chicano students in an urban context. Urban Education, 36(3), 308-342.

Yazzie-Mintz, T. (2008). Creating culture in the here and now: Regenerating rituals in purposeful epistemologies. In M. Benham (Ed.), Indigenous educational models for contemporary practice: In our mother's voice volume II (pp. 13-19). New York, NY: Routledge.

Wilson, S. (2001). What is an indigenous research methodology? Canadian Journal of Native Education, 25(2), 175-182.

Wilson, S. (2003). Progressing toward an indigenous research paradigm in Canada and Australia. Canadian Journal of Native Education, 27(2), 161-178. 